\title{
Effects of Gender and Type 2 Diabetes Mellitus on left Ventricular Structure in a Group of Hypertensive Patients in Erbil-Iraq \\ Salam Naser Zangana (DM, CABMS, FICMS) ${ }^{1}$, Mohamed Sadradin Mahmood(MBChB ,FICMS) ${ }^{2}$ and Namir G Al-Tawil(MBChB, FICMS/CM, FFPH) ${ }^{3}$ Abstract
}

Background: The effects of diabetes mellitus and gender on left ventricular structure in hypertension are still controversial.

Objective: To evaluate the effects of diabetes mellitus and gender on left ventricular structure in a sample of hypertensive patients in Erbil-Iraq.

Patients and Methods: This cross sectional study was conducted in Rizgary hospital, ErbilIraq, between April 2015 and April 2016. A convenient sample of 200 patients (100 males and 100 females), aged $\geq 18$ years were enrolled. Half of the sample (Group I) had diabetes in addition to hypertension, while the other half (Group II) had hypertension only. The effects of diabetes mellitus and gender on left ventricular structure were evaluated in both groups.

Results: In Group I, left ventricular diastolic and systolic dimensions were significantly higher among male patients $(\mathrm{P}=0.023,0.022$ respectively) than female patients. In group II , the mean thickness of posterior wall, left ventricular mass, left ventricular mass index and relative wall thickness was significantly higher among male patients $(\mathrm{P}=0.004,0.016,0.035$ and 0.045 respectively) than female patients. The mean thickness of interventricular septum, posterior wall and relative wall thickness $(\mathrm{P}=0.0013,0.007$ and 0.003 respectively) was significantly higher in diabetic females than non-diabetic females. No significant differences were found between diabetic and non-diabetic males.

Conclusion: There is an obvious effect of gender and diabetes on left ventricular structure. In the hypertensive non-diabetic group, the left ventricular structural changes were significantly seen among male patients than females. In contrary, these changes were significantly seen in diabetic females than non-diabetic females.

Keywords: Diabetes mellitus, Gender, Hypertension, Left ventricular structure.

Corresponding Author: dr_salam2003@yahoo.com

Received: $6^{\text {th }}$ March 2019

Accepted: $10^{\text {th }}$ March 2019

DOI:https://doi.org/10.26505/DJM.17024570306

1,2,3 College of Medicine- Hawler Medical University-Erbil-Iraq. 


\section{Introduction}

Hypertension is a major modifiable risk factor for cardiovascular diseases [1]. It is associated with a high mortality rate, accounting for $\sim 14 \%$ of cardiovascular deaths worldwide [2]. According to World Health Statistics 2012, $40 \%$ of the Iraqi adult populations have elevated blood pressure [3]. Echocardiographic studies in hypertension have shown greater left ventricular (LV) mass in men than in women [4].

Diabetes Mellitus (DM) is a cardiovascular risk factor associated with arterial hypertension and accelerated atherosclerosis [5]. Several studies have suggested that diabetes may be associated with LV structural and functional abnormalities [6]. Other studies mentioned that diabetes was associated with higher LV mass in women but not in men [7].

Patients with diabetes and hypertension are exposed to an exceptionally high risk of cardiovascular death, and are generally thought to need a more intensive risk factor control [8]. Both hypertension and DM may synergistically affect LV structure and function. Left ventricular hypertrophy $(\mathrm{LVH})$ is mediated not only by the mechanical stress of pressure overload, but also by various neurohormonal substances (like insulin) that independently exert trophic effects on myocytes in the heart [9]. The relationships between glucose metabolism abnormalities and LV structure have been described in several reports [10]. However, the findings were controversial [11]. The gender differences were not specifically investigated in this issue. Up to our knowledge, there was no previous study done regarding the same subject in Erbil city. The objective of this study was to find out the effect of gender and type 2 diabetes mellitus on left ventricular structure in a sample of hypertensive patients in Erbil city.

\section{Patients and Methods}

This cross-sectional study was conducted in Rizgary teaching hospital between April 2015 and April 2016. A convenient sample of 200 patients presenting with essential hypertension, aged $\geq 18$ years were enrolled in the study. Those found to have diabetes in addition to hypertension were assigned to group I of the study (100 patients), while group II (100 patients) consisted of hypertensive patients only. All patients were assessed by a detailed history, physical examination, echocardiographic examinations, and any other necessary investigations to document presence of hypertension, DM and/or left ventricular structure abnormalities.

The exclusion criteria were patients with secondary hypertension (polycystic kidney disease, renovascular hypertension, and Cushing syndrome), chronic renal failure, liver disease and type $1 \mathrm{DM}$.

Based on recommendations of the Eighth Report of the Joint National Committee on Prevention, Detection, Evaluation, and Treatment of High Blood Pressure (JNC 8) [12], hypertension was defined as systolic blood pressure (SBP) $\geq 140 \mathrm{mmhg}$ and (DBP) diastolic blood pressure $\geq 90 \mathrm{mmhg}$ for adults aged 18 years and less than 60 years, and systolic blood pressure $\geq 150$ or diastolic 
$\geq 90$ in general population $\geq 60$ years. Blood pressure measurements were taken with a mercury sphygmomanometer. Measurements were made to the nearest $2 \mathrm{~mm} \mathrm{Hg}$, in the sitting position with the arm supported, provided that the patient was at rest in the previous 5 minutes. The mean of two $\mathrm{BP}$ measurements was taken at each visit.

Transthoracic echocardiographic examination was performed by an expert cardiologist in the left lateral position. Standard M-mode, 2-Dimensional and Doppler echocardiographies were performed using (GE brand, Vivid E9, model 2012) echocardiography machine. All dimensions were measured according to established standards of the American Society of Echocardiography [13]. LV mass (LVM) was calculated according to the Devereux formula [14]: LVM=1.04 [(LVDd + IVSth +PWT) 3 (LVDd) 3 ] - 13.6. Thereafter, LV mass index (LVMI) was obtained by the following formula: LVM/body surface area $(\mathrm{g} / \mathrm{m} 2)$ [15]. LVH was defined when LVMI exceeds 115 grams in men and 95 grams in women per meter square body surface area ( $\mathrm{m} 2$ BSA).

The data were collected by interviewing the patients using a questionnaire designed by the researchers. The questionnaire included information about socio-demographic data, hypertension, risk factors (like hyperlipidemia, IHD, obesity, family history), and history of smoking and alcoholism.

Ethical considerations: The study protocol was approved by the ethics committee of the College of Medicine of Hawler Medical University. This study was conducted by using an informed verbal consent from the patients prior to participation in the study. The purpose of the study was carefully explained to each patient.

\section{Statistical analysis}

Data were analyzed using the statistical package for social sciences (SPSS, version 19). Student's $t$ test for two independent samples was used to compare means. A ' $\mathrm{P}$ ' value of $\leq 0.05$ was considered as statistically significant.

\section{Results}

A total of 200 hypertensive patients were enrolled in this study. Half of the sample (Group I) had diabetes mellitus in addition to hypertension, while the other half (Group II) had hypertension only. Basic characteristics, clinical variables and LV echocardiographic parameters of both groups are shown in Table (1). There were no significant statistical differences between the means of the studied parameters of both groups $(\mathrm{p}>$ $0.05)$. 
Effects of Gender and Type 2 Diabetes Mellitus on left Ventricular Structure in a Group of Hypertensive

Patients in Erbil-Iraq

Table (1): Comparison between the means of the two study groups regarding basic characteristics, clinical variables, and echocardiographic parameters

\begin{tabular}{|l||c||c|c|c|c||}
\hline \multicolumn{1}{|c|}{} & \multicolumn{2}{c|}{ Group I (DM + HTN) } & \multicolumn{2}{c|}{ Group II (HTN only) } & \multirow{2}{*}{ p } \\
\cline { 2 - 3 } & Mean & SD & Mean & SD & \\
\hline \hline Age & 55.25 & 11.36 & 53.95 & 10.56 & .403 \\
\hline \hline BMI & 28.80 & 5.13 & 27.73 & 4.94 & .133 \\
\hline \hline SBP & 153.20 & 16.68 & 149.55 & 16.71 & .124 \\
\hline \hline DBP & 94.95 & 14.85 & 92.61 & 9.24 & .182 \\
\hline \hline HT duration & 4.57 & 4.78 & 3.59 & 3.25 & .092 \\
\hline \hline EF & 66.12 & 7.84 & 65.24 & 7.59 & .42 \\
LVH & $58 \%$ & & $52 \%$ & & .11 \\
& & & & & .06 \\
\hline \hline IVS & 12.46 & 2.61 & 11.79 & 2.32 & .31 \\
\hline \hline PW & 11.74 & 2.58 & 11.39 & 2.27 & .74 \\
\hline \hline Left atrium & 33.84 & 4.57 & 33.61 & 5.04 & .46 \\
\hline \hline LVM & 220.42 & 69.38 & 212.93 & 72.27 & .60 \\
\hline \hline LVMI & 118.83 & 36.68 & 116.01 & 38.49 & .17 \\
\hline \hline RWT & .51 & .14 & .48 & .12 & \\
\hline
\end{tabular}

*BMI=Body mass index, EF=Ejection fraction, IVS=Interventricular septum, PW= Posterior wall, RWT=Relative wall thickness.

In the diabetic group Group (I), no inter- parameters (representing LV mass and gender statistical differences were found geometry) as shown in Table (2). regarding the LV echocardiographic

Table (2): Comparison between the means echocardiographic parameters of males and females among group I only

\begin{tabular}{|l||c|c||c|c||c||}
\hline \multirow{2}{*}{$\begin{array}{l}\text { Echocardiographic } \\
\text { parameters }\end{array}$} & \multicolumn{2}{|c|}{ Males } & \multicolumn{2}{c||}{ Females } & \multirow{2}{*}{ p } \\
\cline { 2 - 5 } & Mean & SD & Mean & SD & \\
\hline EF & 64.98 & 6.95 & 67.26 & 8.56 & .147 \\
\hline \hline IVS & 12.33 & 2.62 & 12.59 & 2.61 & .620 \\
\hline \hline PW & 11.50 & 2.49 & 11.98 & 2.67 & .352 \\
\hline Left atrium & 33.40 & 4.14 & 34.28 & 4.97 & .338 \\
\hline \hline LVM & 223.18 & 66.13 & 217.66 & 73.06 & .693 \\
\hline LVMI & 120.22 & 35.52 & 117.44 & 38.11 & .707 \\
\hline \hline RWT & .48 & .14 & .53 & .15 & .088 \\
\hline
\end{tabular}

Echocardiographic parameters of males and females (Group II only) are shown in Table (3). The mean thickness of posterior wall, LV mass, LVM index and relative wall thickness was significantly higher among male patients $(\mathrm{P}=0.004,0.016,0.035$ and 0.045 respectively) than female patients. 
Effects of Gender and Type 2 Diabetes Mellitus on left Ventricular Structure in a Group of Hypertensive

Patients in Erbil-Iraq

Table (3): Comparison between the means echocardiographic parameters of males and females among group II only

\begin{tabular}{|l||c|c||c|c|c||}
\hline \multirow{2}{*}{$\begin{array}{l}\text { Echocardiographic } \\
\text { parameters }\end{array}$} & \multicolumn{2}{c||}{ Males } & \multicolumn{2}{c|}{ Females } & \multirow{2}{*}{ p } \\
\cline { 2 - 6 } & Mean & SD & Mean & SD & \\
\hline \hline EF & 64.74 & 7.30 & 65.74 & 7.91 & .513 \\
\hline IVS & 12.19 & 2.47 & 11.39 & 2.11 & .086 \\
\hline \hline PW & 12.04 & 2.53 & 10.74 & 1.76 & .004 \\
\hline \hline Left atrium & 33.94 & 4.77 & 33.28 & 5.31 & .515 \\
\hline \hline LVM & 230.18 & 81.19 & 195.68 & 57.92 & .016 \\
\hline \hline LVMI & 124.08 & 44.90 & 107.94 & 29.06 & .035 \\
\hline \hline RWT & .51 & .15 & .46 & .09 & .045 \\
\hline
\end{tabular}

In intra-gender comparisons, no significant statistical differences were found in the means of echocardiographic parameters of diabetic and non-diabetic hypertensive male patients Table (4), but diabetic female patients show significant statistical differences regarding the mean thickness of

Table (4): Comparison between the means of echocardiographic parameters of the two study groups, among males only

\begin{tabular}{|l||c|c||c|c||c||}
\hline \multirow{2}{*}{$\begin{array}{l}\text { Echocardiographic } \\
\text { parameters }\end{array}$} & \multicolumn{2}{|c|}{ Group I (DM+HTN) } & \multicolumn{2}{c|}{ Group II (HTN only) } & \multirow{2}{*}{ p } \\
\cline { 2 - 5 } & Mean & SD & Mean & SD & \\
\hline \hline EF & 64.980 & 6.950 & 64.740 & 7.303 & .867 \\
\hline \hline IVS & 12.334 & 2.624 & 12.190 & 2.472 & .778 \\
\hline PW & 11.500 & 2.495 & 12.036 & 2.535 & .289 \\
\hline Left atrium & 33.400 & 4.135 & 33.940 & 4.774 & .547 \\
\hline \hline LVM & 223.180 & 66.126 & 230.180 & 81.194 & .637 \\
\hline \hline LVMI & 120.220 & 35.523 & 124.080 & 44.898 & .635 \\
\hline \hline RWT & .483 & .136 & .506 & .147 & .423 \\
\hline
\end{tabular}

Table (5): Comparison between the means of echocardiographic parameters of the two study groups, among females only

\begin{tabular}{|l||c||c||c|c||c||}
\hline \multirow{2}{*}{$\begin{array}{l}\text { Echocardiographic } \\
\text { parameters }\end{array}$} & \multicolumn{2}{c||}{ Group I (DM+HTN) } & \multicolumn{2}{c||}{ Group II (HTN only) } & \multirow{2}{*}{ p } \\
\cline { 2 - 5 } & Mean & SD & Mean & SD & \\
\hline EF & 67.260 & 8.561 & 65.740 & 7.912 & .359 \\
\hline \hline IVS & 12.594 & 2.610 & 11.392 & 2.111 & .013 \\
\hline \hline PW & 11.984 & 2.673 & 10.744 & 1.760 & .007 \\
\hline Left atrium & 34.280 & 4.965 & 33.280 & 5.311 & .333 \\
\hline LVM & 217.660 & 73.064 & 195.680 & 57.916 & .099 \\
\hline LVMI & 117.440 & 38.108 & 107.940 & 29.061 & .164 \\
\hline \hline RWT & .532 & .147 & .456 & .091 & .003 \\
\hline
\end{tabular}




\section{Discussion}

In the present study, LVM was significantly higher in male patients than females in Group (II). Effects of gender on LVM are somewhat indefinite [7]. Several studies have identified sex-related differences in the response to chronic pressure overload, with men having higher LV mass than women [4, 16, 17]. Regarding other echocardiographic parameters and despite the fact that LVH was not statistically significant but the means of posterior wall thickness, LVM index and relative wall thickness (RWT) were significantly higher among hypertensive non-diabetic Group (II) male patients than female patients. In the determination of left ventricular adaptive process that takes place in the over-loaded ventricle, fundamental components namely wall thickness must be taken into account [18]. Parietal thickness and its relation to LV chamber size has been recognized as a measure of hypertrophy for more than 30 years [19]. RWT (which depends on the posterior wall thickness) provides information regarding LV geometry independent of other calculations [20]. In the hypertensive diabetic group, no inter-gender statistical differences were found regarding the above parameters but only left ventricular diastolic and systolic dimensions were significantly higher among male patients.

The prevalence of $\mathrm{LVH}$ in patients with essential hypertension is ranging from 12 to $70 \%$, depending on clinical characteristics of the population studied and largely on the measurement technique used [21].
In the present study, LVH was present in $52 \%$ of patients with hypertension alone (non-diabetic group). This result is within the above-mentioned range.

In intra-gender comparisons, no significant differences were found in diabetic and nondiabetic hypertensive male patients, but diabetic females show significant differences regarding interventricular septum, posterior wall and RWT. Despite being not statistically significant, but other parameters like LVM and LVM index were higher in diabetic women. Many studies have shown that DM affects the cardiac function and structure independent of hypertension or any other known risk factors [22]. Diabetes has been implicated as an important determinant of left ventricular mass in many studies. Myocardial and systemic mechanisms, as an increased extra-cellular matrix, vascular hypertrophy, and vasoconstriction have been attributed to this hypertrophic response [5-8]. It is now well recognized that insulin directly promotes myocyte hypertrophy independent of its effects on systemic arterial pressure [10]. In addition to circulating insulin, insulin growth factor-1 is also an independent determinant of LVM and geometry in essential hypertension [9]. However, Galvin et al [11] concluded that insulin resistance and hyperinsulinemia are not independent predictors of LVM in humans. In this study, the prevalence of LVH was higher (58\%) in patients with both hypertension and DM than in patients with hypertension alone, although it was statistically not significant. The high 
Effects of Gender and Type 2 Diabetes Mellitus on left Ventricular Structure in a Group of Hypertensive

Patients in Erbil-Iraq

prevalence of LVH in our study is comparable with previously reported data. Somaratne et al [23] demonstrated that LVH was common (56\%) among patients with type2 DM with no known cardiac, cerebrovascular or peripheral vascular disease. Echocardiographic LVH was found in $(22-51 \%)$ of Australian diabetes clinic attendees [24]. A higher prevalence of echocardiographic LVH (71\%) was noted in diabetes clinic attendees in Dundee, Scotland [25].

\section{Conclusions}

There is an obvious effect of gender and diabetes on left ventricular structure. In the hypertensive non-diabetic group, the left ventricular structural changes were significantly seen among male patients than females. In contrary, these changes were significantly seen in diabetic females than non-diabetic females.

\section{Recommendations}

1- Large scale prospective studies are needed in the future to evaluate the impact of gender and diabetes mellitus in hypertensive patients on left ventricular structure and function, and the development of LVH.

2- More studies are needed to evaluate the effect of type $1 \mathrm{DM}$ on left ventricular structure and function, and to reveal if there is any gender difference to effect.

\section{References}

[1]Mendis S, Puska P, Norrving B, editors. Global Atlas on Cardiovascular Disease Prevention and Control. World Health Organization (in collaboration with the
World Heart Federation and World Stroke Organization), Geneva 2011.

[2]WHO Regional Office for South East Asia. Hypertension fact sheet. Available from:http://www.searo.who.int/linkfiles/non_ communicable_diseases_hypertension-fs.pdf. Accessed 21 March 2012.

[3]World Health Organization: World Health Statistics 2012. Part II, Highlighted Topics. In Geneva: WHO Press; 2012: 34. [4] Akintunde AA, Oladosu Y, Opadijo OG: Gender specific pattern of left ventricular cardiac adaptation to hypertension and obesity in a tertiary health facility in Nigeria. Afr Health Sci. 2013 Sep; 13(3): 595-600. [5] M Benjamin and Maddox T: Diabetes and cardiovascular disease: Epidemiology, biological mechanisms, treatment recommendations and future research. World J Diabetes. 2015 Oct 10; 6(13): 1246-1258.

[6] Devereux RB, Roman MJ, Paranicas M, O'Gardy MJ, Lee ET, et al. Impact of diabetes on cardiac structure and function: The Strong Heart Study. Circulation 2000; 101:2271-76.

[7]Gerdts E, Okin P, de Simone G , Cramariuc D , Wachtell K , Boman K , et al : Gender Differences in Left Ventricular Structure and Function During Antihypertensive Treatment The Losartan Intervention for Endpoint Reduction in Hypertension Study. Hypertension. 2008;51:1109-1114.

[8]Morrish NJ, Wang SL, Stevens LK, Fuller $\mathrm{JH}$, Keen H: Mortality and causes of death in the WHO Multinational Study of Vascular 
Effects of Gender and Type 2 Diabetes Mellitus on left Ventricular Structure in a Group of Hypertensive

Patients in Erbil-Iraq

Disease in Diabetes. Diabetologia 2001; 44: S14-S21.

[9]Ilerci A , Devereux RB, Roman MJ, Paranicas M, O'Grady MJ, Lee ET, et al: Associations of Insulin Levels With Left Ventricular Structure and Function in American Indians: The Strong Heart Study. Diabetes 2002 May; 51(5): 1543-1547.

[10] Devereux RB, Roman MJ, Paranicas M, O'Grady MJ, Lee ET, et al : Impact of diabetes on cardiac structure and function: the Strong Heart Study. Circulation 2000,101 : $2271-2276$.

[11]Galvan AQ, Galetta F, Natali A, Muscelli E, Sironi AM, Cini G,et al: Insulin resistance and hyperinsulinemia: No independent relation to left ventricular mass in humans. Circulation 2000, 102:2233-38. [12]Paul AJ, Suzanne O, Barry LC, William CC, Cheryl DH, Joel H, et al. 2014 Evidence-Based Guideline for the Management of High Blood Pressure in Adults. Report From the Panel Members Appointed to the Eighth Joint National Committee (JNC 8). JAMA. 2014; 311(5):507-20.

[13]lang RM, Bierig M, Devereux RB, Flachskampf FA, Foster E, Pellikka PA, et al. Chamber Quantification Writing Group. Recommendations for Chamber Quantification : A report from the American Society of Echocardiography's Guidelines and Standards Committee and the Chamber Quantification Writing Group, Developed in conjunction with the European Association of Echocardiography, a branch of The
European Society of Cardiology. J Am Soc Echocardiogr 2005; 18:1440-63.

[14] Lang, R.M., Bierig, M., Devereux, R.B. et al. Recommendations for chamber quantification. Eur J Echocardiogr. 2006; 7: 79.

[15]Okin PM, Devereux RB, Jer S. Regression of electrocardiographic left ventricular hypertrophy during antihypertensive treatment and the prediction of major cardiovascular events. JAMA 2004;292:2343-49.

[16]Escudero EM, Orlowski A, Díaz A, Pinilla OA, Ennis IL, Aiello EA. Gender differences in cardiac left ventricular mass and function: Clinical and experimental observations. Cardiol J. 2014; 21(1):53-9.

[17]Salton CJ, Chuang ML, O’Donnell CJ et $a$ l. Gender differences and normal left ventricular anatomy in an adult population free of hypertension: A cardiovascular magnetic resonance study of the Framingham Heart Study Offspring cohort. J Am Coll Cardiol, 2002; 39: 1055-1060.

[18]Spirito P, Bellone P, Harris KM, Bernabo P, Bruzzi P, Maron BJ. Magnitude of left ventricular hypertrophy and risk of sudden death in hypertrophic cardiomyopathy. N Engl J Med 2000;342:1778-85.

[19] V Puntmann, R Gebker, S Duckett, J Mirelis, B Schnackenburg, M Graefe, et al: Left ventricular chamber dimensions and wall thickness by cardiovascular magnetic resonance: comparison with transthoracic echocardiography. European Heart Journal Cardiovascular Imaging (2013) 14, 240-246. 
[20]Li L, Shigematsu Y, Hamada M, Hiwada $\mathrm{K}$ : Relative wall thickness is an independent predictor of left ventricular systolic and diastolic dysfunctions in essential hypertension. Hypertens Res 2001; 24:49399.

[21]Okin PM, Devereux RB, Jern S, Kjeldsen SE, Julius S, Nieminen M et al.: Losartan Intervention for Endpoint reduction in hypertension Study Investigations. Regression of electrocardiographic left ventricular hypertrophy by losartan versus atenolol: The Losartan Intervention for Endpoint reduction in Hypertension (LIFE(Study. Circulation 2003, 108:684-90. [22]Fang ZY, Prins JB, Marwick TH . Diabetic Cardiomyopathy: Evidence Mechanisms and Therapeutic Implications. Endocr Rev 2004; 25: 543-67.

[23]Jithendra B S, Gillian A W, Katrina K P, Mariska M B, Gina W, Ann Pearl, et al. Screening for left ventricular hypertrophy in patients with type 2 diabetes mellitus in the community. Cardiovasc Diabetol. 2011; 10: 29.

[24]Srivastava PM, Calafiore P, Macisaac RJ, Patel SK, Thomas MC, Jerums G, et al. Prevalence and predictors of cardiac hypertrophy and dysfunction in patients with Type 2 diabetes. Clinical Science. 2008;114(4):313-20.

[25]Dawson A, Morris AD, Struthers AD. The epidemiology of left ventricular hypertrophy in type 2 diabetes mellitus. Diabetologia. 2005;48(10):1971-1979. 